\title{
Formation of the oil flax yield in the conditions of the Sverdlovsk region
}

\author{
A.P. Kolotov* \\ Ural Federal Agrarian Research Center of the Ural Branch of the Russian Academy of Sciences, \\ Yekaterinburg, Russia
}

\begin{abstract}
Oil flax was grown on gray forest soils of the Middle Urals in the period 2012-2020. The purpose of the research was to identify changes in the yield structure of various oil flax varieties and its productivity, depending on the growing conditions. The research used the method of field experience and statistical processing of experimental data. It was found that the conditions of the year of growing oil flax had a noticeable effect on the number of formed capsules on the plant, seeds in one capsule and the mass of 1000 seeds. Small seeds of all varieties were formed in the conditions of warm and dry 2012, and the largest seeds were obtained in cool and wet 2015. The average yield of oil flax seeds was 1.90-2.14 t/ha, the maximum yield was $2.88 \mathrm{t} / \mathrm{ha}$, provided by the Ural variety in 2017 . The yield variability level by $77.7 \%$ was determined by environmental conditions, the influence of genotypes caused $6.6 \%$ of yield variation, and the interaction of genotype $\mathrm{x}$ environment $-14.9 \%$.
\end{abstract}

\section{Introduction}

According to the specialists of the FSBI "Center for Agroanalytics", over the past ten years in the Russian Federation, there has been a constant increase in the acreage of oil flax. The country is one of the three world leaders in the production and export of flax seeds. [1; 2]. The valuable agricultural crop is becoming more widespread in the Middle Urals. Thus, according to State statistics, in the Sverdlovsk region in 2019 and in 2020, it was grown on 5.2 and 6.2 thousand hectares, respectively. A significant increase in acreage is also observed in the neighboring Chelyabinsk and Kurgan regions [3]. It should be noted that until 2012, oil flax was practically unknown in agricultural enterprises of the Middle Urals [4, p. 282].

Traditionally, oilseed flax is considered a heat-loving crop and it was cultivated mainly in the southern regions of the Russian Federation [5, p. 180]. Numerous studies and practical experience of agricultural enterprises in various regions of the Russian Federation have proved the high efficiency of the oil flax cultivation. At the same time, there is a high and stable demand for flax seeds both within the country and on the foreign market, due to the valuable qualities of oilseeds $[6$, p.84; 7, p. $64 ; 8$, p. 84]. All this will contribute to

\footnotetext{
* Corresponding author: ankolotov@yandex.ru
} 
strengthening of the economic potential of the Ural Federal District and generally corresponds to the plans for a significant increase in the export of agricultural products [9, p. 10].

The possibility of obtaining high yields of oil flax not only in the southern regions of the country, but also in the middle zone of Russia, where it used to belong to sparsely distributed crops, including in the soil and climatic conditions of the Middle Urals, is scientifically justified [10, p. 40; 11, p.605].

The technology of cultivation of oil flax is constantly being improved, the main technological techniques are being specified, the effectiveness of the use of modern equipment and plant protection products is being studied [12, p. $67 ; 13 ; 14$, p.61]. In many regions of the country, breeding work with the oil flax crop has intensified, and the register of varieties approved for use in production is updated annually. Thus, for the conditions of the Middle Urals, a new variety of oil flax, Uralsky, was created, which is characterized by high productivity, seed quality and technological efficiency during harvesting $[15 ; 16]$.

Oil flax not only provides increased profitability in cultivation, but it is also a good precursor for grain crops [17, p. 629]. The importance of oil flax in the national economy is determined by the versatile use of its seeds for technical, feed and food purposes [18, $\mathrm{p}$. 28]. It is no accident that extensive research on the oil flax culture is carried out in many foreign countries - Canada, the USA, the Czech Republic, etc. [19; 20]. Not only the issues of breeding and cultivation technology, but also the prospects for the use of genetically modified oil flax plants are being studied [21].

Until now, the study of the oil flax culture and the improvement of its cultivation technology have been carried out in the traditional regions of its cultivation. For the Middle Urals, this is a completely new agricultural plant, so research aimed at identifying patterns of formation of oil flax yield and having the ultimate goal of increasing its productivity is of particular relevance.

The purpose of the research is to identify changes in the yield structure of various oil flax varieties and its productivity, depending on the growing year conditions.

\section{Materials and methods of research}

The object of the study was three varieties of oil flax: Severny, Uralsky and LM 98, which were grown in the experimental fields of the Ural Research Institute of Agricultural Sciences during 2012-2020. All of them are included in the State Register of Breeding Achievements in the Sverdlovsk region, the Severny variety is usually accepted as a standard for scientific research and variety testing.

When setting up field experiments and performing accompanying observations and accounting, we were guided by the methodology of the All-Russia Research Institute of Oilseed Cultures n.a. V. S. Pustovoit [22], statistical processing of experimental data was performed according to B.A. Dospekhov [23].

Field experiments were carried out on gray forest heavy loamy soils, which have the highest specific weight in agricultural enterprises of the Middle Urals. Agrochemical parameters were determined annually in the samples selected before the experiments were started. The content of humus and basic nutrients, as well as the acidity and the amount of exchange bases in the arable layer, although different in the experimental plots in different years, were generally typical for gray forest soils: $\mathrm{pH}-4.2-5.5$, humus $-3.03-4.62 \%$, easily hydrolyzable nitrogen $-8.1-17.3 \mathrm{mg} / 100 \mathrm{~g}$ of soil, mobile phosphorus $-11.6-28.8 \mathrm{mg} / 100$ 
$\mathrm{g}$ of soil, exchangeable potassium $-7.2-15.9 \mathrm{mg} / 100 \mathrm{~g}$ of soil, hydrolytic acidity $-3.8-10.3$ $\mathrm{mmol} / 100 \mathrm{~g}$ of soil, the sum of exchange bases $-23.9-28.9 \mathrm{mmol} / 100 \mathrm{~g}$ of soil. According to the steam precursor, mineral nutrition elements were sufficient to form the yield of oil flax seeds up to $3 \mathrm{t} / \mathrm{ha}$. In order to reduce the impact of the diversity of soil fertility on the growth and development of plants, in all years before sowing, a minimum dose of fertilizers was applied $-\mathrm{N}_{30} \mathrm{P}_{30} \mathrm{~K}_{30}$.

Oil flax was sown with a rate of 9 million germinating seeds per hectare. Variants of experiments were laid in three-fourfold repetition, the accounting area of the plot was in different years from 10 to $15 \mathrm{~m}^{2}$. Sowing of seeds was carried out by breeding seeders SKS-6-10 and "Klen", harvesting - by a Sampo-130 combine harvester in a single-phase way.

According to weather conditions, 2012 can be described as warm and dry, 2013 - warm and close to normal in terms of moisture, 2014 - cool and humid, 2015 - extremely cool and humid, 2016 - extremely hot and dry. In terms of agrometeorological conditions, 2017 and 2018 were close to normal, although in some periods there were significant deviations from the long-term average, both in temperature and precipitation. A feature of 2019 can be considered a lack of heat and excessive moisture in the second half of summer, which delayed the maturation of seeds, so the forced measure was the desiccation of oil flax seedings. The year 2020 was unique, when after sowing in well-warmed soil, a long period of cool weather followed, replaced by a prolonged drought. At the end of the growing season of oil flax, cool and rainy weather was again observed, which led to a decrease in the sowing qualities of the seeds.

\section{Results and discussion}

According to the rate of its development, oil flax belongs to plants whose growing season does not exceed 80-85 days. Nevertheless, in the geographical latitude of the Middle Urals, the period from germination to full ripeness of seeds even in early-maturing varieties of oil flax often exceeded 90 days, and in medium-maturing LM 98 - more than 100 days (Table $1)$.

Table 1. The duration of the growing season and the length of plants of oil flax varieties under different environmental conditions.

\begin{tabular}{|c|c|c|c|c|c|c|c|c|c|c|}
\hline \multirow[t]{2}{*}{ Indicator } & \multicolumn{9}{|c|}{ Years } & \multirow[t]{2}{*}{ Average } \\
\hline & 2012 & 2013 & 2014 & 2015 & 2016 & 2017 & 2018 & 2019 & 2020 & \\
\hline \multicolumn{11}{|c|}{ Severny variety } \\
\hline $\begin{array}{l}\text { Vegetation } \\
\text { period, } \\
\text { day }\end{array}$ & 87 & 83 & 108 & 107 & 94 & 113 & 101 & 103 & 94 & 99 \\
\hline $\begin{array}{c}\text { Plant } \\
\text { length, } \mathrm{cm}\end{array}$ & 49 & 51 & 61 & 61 & 61 & 64 & 57 & 53 & 61 & 58 \\
\hline \multicolumn{11}{|c|}{ Uralsky variety } \\
\hline $\begin{array}{l}\text { Vegetation } \\
\text { period, } \\
\text { day }\end{array}$ & 89 & 86 & 107 & 107 & 89 & 113 & 101 & 103 & 92 & 98 \\
\hline $\begin{array}{c}\text { Plant } \\
\text { length, } \mathrm{cm}\end{array}$ & 48 & 43 & 60 & 58 & 53 & 64 & 56 & 52 & 58 & 55 \\
\hline \multicolumn{11}{|c|}{ LM 98 variety } \\
\hline Vegetation & 96 & 93 & 125 & 114 & 101 & 116 & 104 & 113 & 105 & 107 \\
\hline
\end{tabular}




\begin{tabular}{|c|c|c|c|c|c|c|c|c|c|c|}
\hline $\begin{array}{c}\text { period, } \\
\text { day }\end{array}$ & & & & & & & & & & \\
\hline $\begin{array}{c}\text { Plant } \\
\text { length, cm }\end{array}$ & 50 & 50 & 70 & 60 & 62 & 66 & 60 & 63 & 68 & 61 \\
\hline
\end{tabular}

This indicator is of exceptional importance when selecting varieties of oil flax for growing in climatic conditions with limited heat resources. The vegetation period of less than 90 days was observed in the Severny and Uralsky varieties in 2012 and 2013, and in the Uralsky variety in 2016. The variation coefficient of the indicator of the growing season duration was at the level of 9.7-10.2\%, which indicates an average or insignificant variability of this trait. The LM 98 variety matured by average 8-9 days later than the precocious Severny and Uralsky varieties. Earlier it was noted that at late sowing dates, plants of the LM 98 variety did not have time to form full-fledged seeds before the onset of autumn dirty weather. It was found that when sowing in the third decade of May, starting with the "herringbone" phase, there was a delay in the development of oil flax plants and the full ripeness phase occurred in mid-September, when precipitation often falls in the Middle Urals at low air temperatures. The plant length changed slightly over the years of the research in the Severny variety $(\mathrm{V}=9.2 \%)$ and to an average extent in the Uralsky and LM 98 varieties $(\mathrm{V}=11.6-11.7 \%)$. The last variety in all years was taller, the difference in length compared to the Uralsky variety in some years reached $10 \mathrm{~cm}$. Despite this, the LM 98 variety is resistant to lodging and is suitable for mechanized harvesting by grain combines.

Although the seeding rate in all the years of the research was the same -9 million germ. seeds per 1 ha, but due to different field germination of flax seeds, different plant survival during growth and development, in experimental crops before harvesting ranged from 389$427 \mathrm{pcs} . / \mathrm{m}^{2}$ to $685-715 \mathrm{pcs} . / \mathrm{m}^{2}$. The highest planting density of oil flax was noted in 2012 , while the number of capsules on the plant did not exceed 6.8-8.2 pcs. For the entire period of observations, each plant of oil flax, regardless of the variety, formed an average of 10-11 capsules (Table 2). Statistical processing of experimental data has shown that there is a significant variability of this trait depending on the conditions of the year. The coefficient of variation was $30.8 \%$ for the Ural variety, $30.9 \%$ for the LM 98 variety and $38.2 \%$ for the Severny variety. The largest number of capsules per 1 plant (15.4-16.9 pcs.) was formed in the favorable environmental conditions in 2017. This indicator has an average negative correlation with the number of productive plants per unit area $(\mathrm{r}=-0.46)$. As a rule, the greater the density of standing plants, the less buds and flowers are formed in the inflorescence, and capsules, respectively.

Table 2. Yield of oil flax varieties and its structure in the years of research.

\begin{tabular}{|c|c|c|c|c|c|c|c|c|c|c|}
\hline \multirow[t]{2}{*}{ Indicator } & \multicolumn{9}{|c|}{ Years } & \multirow[t]{2}{*}{ Average } \\
\hline & 2012 & 2013 & 2014 & 2015 & 2016 & 2017 & 2018 & 2019 & 2020 & \\
\hline \multicolumn{11}{|c|}{ Severny variety } \\
\hline $\begin{array}{c}\text { Number of } \\
\text { plants per } 1 \\
\mathrm{~m}^{2}, \text { pcs. }\end{array}$ & 715 & 546 & 561 & 389 & 570 & 504 & 596 & 554 & 453 & 543 \\
\hline $\begin{array}{l}\text { Number of } \\
\text { capsules per } \\
1 \text { plant, pcs. }\end{array}$ & 7.5 & 7.0 & 13.0 & 13.4 & 9.8 & 17.7 & 7.3 & 6.1 & 8.8 & 10.1 \\
\hline $\begin{array}{c}\text { Number of } \\
\text { seeds in } 1\end{array}$ & 4.6 & 6.2 & 6.5 & 5.1 & 6.7 & 5.8 & 6.1 & 7.1 & 6.5 & 6.1 \\
\hline
\end{tabular}




\begin{tabular}{|c|c|c|c|c|c|c|c|c|c|c|}
\hline $\begin{array}{l}\text { capsule, } \\
\text { pcs. }\end{array}$ & & & & & & & & & & \\
\hline $\begin{array}{c}\text { Mass of } \\
1000 \text { seeds, } \\
\mathrm{g}\end{array}$ & 6.54 & 8.47 & 7.59 & 9.00 & 7.35 & 7.67 & 7.79 & 7.18 & 8.43 & 7.78 \\
\hline Yield, t/ha & 1.61 & 1.79 & 2.12 & 2.20 & 1.65 & 2.30 & 1.94 & 1.80 & 2.20 & 1.96 \\
\hline \multicolumn{11}{|c|}{ Uralsky variety } \\
\hline $\begin{array}{l}\text { Number of } \\
\text { plants per } 1 \\
\mathrm{~m}^{2} \text {, pcs. }\end{array}$ & 692 & 653 & 567 & 380 & 672 & 684 & 542 & 599 & 471 & 584 \\
\hline $\begin{array}{l}\text { Number of } \\
\text { capsules per } \\
1 \text { plant, pes. }\end{array}$ & 6.8 & 6.6 & 12.1 & 13.1 & 10.2 & 15.4 & 10.0 & 7.1 & 8.5 & 10.0 \\
\hline $\begin{array}{l}\text { Number of } \\
\text { seeds in } 1 \\
\text { capsule, } \\
\text { pcs. }\end{array}$ & 5.6 & 5.2 & 7.2 & 5.6 & 8.5 & 6.0 & 5.5 & 7.3 & 6.7 & 6.4 \\
\hline $\begin{array}{c}\text { Mass of } \\
1000 \text { seeds, } \\
\mathrm{g}\end{array}$ & 6.51 & 8.34 & 7.90 & 9.10 & 7.22 & 8.00 & 7.60 & 7.24 & 8.62 & 7.84 \\
\hline Yield, t/ha & 1.72 & 1.60 & 2.33 & 2.25 & 2.14 & 2.88 & 2.03 & 1.97 & 2.31 & 2.14 \\
\hline \multicolumn{11}{|c|}{ LM 98 variety } \\
\hline $\begin{array}{l}\text { Number of } \\
\text { plants per } 1 \\
\mathrm{~m}^{2} \text {,pcs. }\end{array}$ & 685 & 685 & 684 & 427 & 604 & 551 & 529 & 595 & 462 & 580 \\
\hline $\begin{array}{l}\text { Number of } \\
\text { capsules per } \\
1 \text { plant, pcs. }\end{array}$ & 8.2 & 8.1 & 12.7 & 12.3 & 14.2 & 16.9 & 8.9 & 6.3 & 11.3 & 11.0 \\
\hline $\begin{array}{l}\text { Number of } \\
\text { seeds in } 1 \\
\text { capsule, } \\
\text { pcs. }\end{array}$ & 3.7 & 6.0 & 8.4 & 6.7 & 8.2 & 6.8 & 8.1 & 7.0 & 7.4 & 6.9 \\
\hline $\begin{array}{c}\text { Mass of } \\
1000 \text { seeds, } \\
\mathrm{g}\end{array}$ & 4.23 & 5.38 & 5.16 & 6.50 & 5.25 & 5.50 & 5.48 & 5.24 & 5.26 & 5.33 \\
\hline Yield, t/ha & 0.88 & 1.68 & 2.21 & 2.18 & 1.76 & 2.76 & 1.84 & 1.74 & 2.03 & 1.90 \\
\hline
\end{tabular}

The indicator of the number of seeds in one capsule was less variable $(\mathrm{V}=13.0-21.0 \%)$. In each capsule of plant inflorescences of the studied oil flax varieties, an average of 6.1 to 6.9 pieces of seeds were formed. This indicator was the highest in the LM 98 variety, for which smaller capsules and seeds are typical.

The average mass of 1000 seeds in the Severny and Uralsky varieties was $2.45-2.51 \mathrm{~g}$ more than in the small-seeded variety LM 98. Although the seed size is determined by the plant genotype, environmental conditions also have a noticeable effect on the value of this indicator within a single variety. For example, in the Uralsky variety, it varied from $6.51 \mathrm{~g}$ to $9.10 \mathrm{~g}(\mathrm{~V}=23.9 \%)$, and in the LM 98 variety - from $4.23 \mathrm{~g}$ to $6.50 \mathrm{~g}(\mathrm{~V}=10.8 \%)$. Small seeds in all varieties were formed in the conditions of warm and dry 2012, and the largest seeds were obtained in cool and wet 2015.

The quantitative indicators of the crop structure of oil flax plants considered above determined its value, which for 9 years of research varied from $1.90 \mathrm{t} / \mathrm{ha}$ to $2.14 \mathrm{t} / \mathrm{ha}$. The most productive was the new Uralsky variety, which was created jointly with the breeders 
of the All-Russian Flax Institute and included in the State Register of Breeding Achievements approved for use since 2017 in three regions of the Russian Federation.

Statistical processing of the obtained data on seed yield revealed the average yield variability in the Severny and Uralsky varieties ( $\mathrm{V}=13.1 \%$ and $17.6 \%$, respectively). The variation coefficient was higher in the LM 98 variety $(26.7 \%)$, which is characterized by a long growing season and reacts more strongly to changing environmental conditions over the years.

The best conditions for the growth and development of the studied varieties were formed in 2017, when the maximum yield of all the studied varieties was obtained. Year 2012 can be considered as the most unfavorable, when a low yield of oil flax seeds was obtained. The reaction of all varieties to the environmental conditions of this year was manifested in the formation of a relatively small number of capsules per 1 plant, seeds in one capsule, as well as the lowest mass of 1000 seeds. Good field germination and the planting density of oil flax in this year did not compensate for the decrease in yield due to poor indicators of the crop structure.

Two-factor variance analysis ANOVA was used to identify the role of genotypes, environmental conditions, and their interaction in yield variability and biometric indicators of the elements of its structure. The Fisher test was used to test the statistical significance. The level of statistical significance was set at $\mathrm{P}<0.05$. According to the results of the variance analysis, the variability of the yield value by $77.7 \%$ was determined by the environmental conditions, the influence of genotypes caused $6.6 \%$ of the yield variation, and the interaction of genotype $\mathrm{x}$ environment $-14.9 \%$. The conditions of the oil flax growing year had a strong impact on the number of plants to harvest and the number of capsules per 1 plant. The greatest influence on the change in the mass index of 1000 seeds was exerted by the plant genotype ( $75 \%$ ), and to a lesser extent - the conditions of the year and the interaction of the variety $\mathrm{x}$ year. This fact should be taken into account when selecting varieties for use in the production and breeding of oil flax. The variation of the indicator of the number of seeds in 1 capsule was almost completely determined by the environmental conditions and the variety x year interaction (Table 3 ).

Table 3. Variance analysis of quantitative indicators of structure elements of yield of oil flax varieties (2012-2020).

\begin{tabular}{|c|c|c|c|c|c|c|}
\hline $\begin{array}{l}\text { Source } \\
\text { variations }\end{array}$ & $\begin{array}{l}\text { Amount } \\
\text { of squares, } \\
\text { SS }\end{array}$ & $\begin{array}{l}\text { Number of } \\
\text { degrees of } \\
\text { freedom, } \mathrm{df}\end{array}$ & $\begin{array}{l}\text { Middle } \\
\text { squares, } \\
\text { MS }\end{array}$ & $\begin{array}{l}\text { Factor } \\
\text { share, \% }\end{array}$ & $\mathrm{F}_{\text {fact }}$ & $F_{\text {theor. }}$ \\
\hline \multicolumn{7}{|c|}{ Number of plants per $1 \mathrm{~m}^{2}$, pes. } \\
\hline Variety & 27932 & 2 & 13966 & 3.9 & 24.4 & 3.2 \\
\hline Year & 578362 & 8 & 72295 & 79.7 & 505.6 & 2.1 \\
\hline Variety $\mathrm{x}$ year & 118192 & 16 & 7387 & 16.3 & 103.3 & 1.8 \\
\hline Remainder (error) & 1144 & 54 & 21 & 0.1 & & \\
\hline Total & 725630 & & & & & \\
\hline \multicolumn{7}{|c|}{ Number of capsules per 1 plant, pcs. } \\
\hline Variety & 17,5 & 2 & 8.8 & 2.0 & 3.43 & 3.2 \\
\hline Year & 793,0 & 8 & 99.1 & 90.3 & 155.4 & 2.1 \\
\hline Variety $\mathrm{x}$ year & 62,2 & 16 & 3.9 & 7.1 & 12.1 & 1.8 \\
\hline Remainder (error) & 5,1 & 54 & 0.1 & 0.6 & & \\
\hline Total & 877,8 & & & & & \\
\hline \multicolumn{7}{|c|}{ Number of seeds in 1 capsule, pcs. } \\
\hline Variety & 4,9 & 2 & 2.5 & 4.3 & 4.4 & 3.2 \\
\hline
\end{tabular}




\begin{tabular}{|c|c|c|c|c|c|c|}
\hline Year & 83,0 & 8 & 10.4 & 72.8 & 75.4 & 2.1 \\
\hline Variety $\mathrm{x}$ year & 25,0 & 16 & 1.6 & 21.9 & 22.7 & 1.8 \\
\hline Remainder (error) & 1,1 & 54 & 0.1 & 1.0 & & \\
\hline Total & 114,0 & & & & & \\
\hline \multicolumn{7}{|c|}{ Mass of 1000 seeds, $g$} \\
\hline Variety & 110,3 & 2 & 55.1 & 75.0 & 1103.0 & 3.2 \\
\hline Year & 33,2 & 8 & 4.2 & 22.6 & 332.0 & 2.1 \\
\hline Variety $\mathrm{x}$ year & 3,5 & 16 & 0.2 & 2.4 & 35.0 & 1.8 \\
\hline Remainder (error) & 0,1 & 54 & 0.1 & 0.0 & & \\
\hline Total & 147,1 & & & & & \\
\hline \multicolumn{7}{|c|}{ Yield, t/ha } \\
\hline Variety & 0,8 & 2 & 0.4 & 6.6 & 8.0 & 3.2 \\
\hline Year & 9,4 & 8 & 1.2 & 77.7 & 94.0 & 2.1 \\
\hline Variety $\mathrm{x}$ year & 1,8 & 16 & 0.1 & 14.9 & 18.0 & 1.8 \\
\hline Remainder (error) & 0,1 & 54 & 0.0 & 0.8 & & \\
\hline Total & 12,1 & & & & & \\
\hline
\end{tabular}

\section{Conclusions}

With the optimal density of oil flax standing before harvesting, 570-580 pieces per square meter, each plant on average formed 10-12 capsules containing 6-7 fully filled seeds. It was found that the conditions of the year of growing oil flax had a noticeable effect on the number of formed capsules on the plant, seeds in one capsule and the mass of 1000 seeds. Small seeds of all varieties were formed in the conditions of warm and dry 2012, and the largest seeds were obtained in cool and wet 2015. The average yield of oil flax seeds was $1.90-2.14 \mathrm{t} / \mathrm{ha}$, reaching the level of $2.30-2.88 \mathrm{t} / \mathrm{ha}$ under favorable conditions in 2017 . The most productive was the Uralsky variety, which is recommended along with the Severny variety for cultivation in agricultural enterprises of the Middle Urals. The yield variability level by $77.7 \%$ was determined by environmental conditions, the influence of genotypes caused $6.6 \%$ of yield variation, and the interaction of variety x year $-14.9 \%$.

\section{Acknowledgment}

The research was carried out within the framework of the State Task of the Ministry of Science and Higher Education of the Russian Federation on the topic "Creation of a new breeding material with increased productive properties, adapted to global climate change, negative impact of anthropogenic factors, resistant to pests and diseases, with specified consumer properties".

\section{References}

1. Linseed world primary production. Database of Food and Agriculture Organization (FAO) URL: http://www.fao.org/faostat/en\#data/QC (access date: 24.01.2019)

2. Flax is in great price, URL: http:// www.rosflaxhemp.ru/publikacii.html/id3475 (access date 08.01 .2021$)$

3. Crown flax (oilseed). Sown areas, URL: http:// www.gks.ru (access date 24.01.2021) 
4. A.P. Kolotov, O.V. Sinyakova, N.A. Kiprushkina, Agroindustrial Complex of Russia, 23(2), 282-287 (2016)

5. Innovative technologies for the cultivation of oilseed crops, 256 (Krasnodar, Prosveshchenie-Yug, 2017)

6. A.S. Bushnev, T.N. Luchkina, G.I. Orekhov, Oilseed crops, 3(183), 84-91 (2020)

7. Yu.V. Mamyrko, K.M. Krivoshlykov, A.S. Bushnev, S.P. Podlesny, T.N. Luchkina, Scientific-technical Bul. of the VNIIMK, 3(175), 64-71 (2018)

8. T.I. Kobyakova, L.V. Ufimtseva, Oilseed crops, 3(185), 83-87 (2020)

9. The world market - time of global changes, Nivy Rossii, 3(158), 10 (2018)

10. V.N. Goreeva, I.Sh. Fatykhov, E.V. Korepanova, K.V. Korepanova, Achievements of science and technology of the agroindustrial complex, 30(1), 40-43 (2016)

11. A.P. Kolotov, N.A. Kiprushkina, Agroindustrial Complex of Russia, 24(3), 604-608 (2017)

12. A.S. Bushnev, F.I. Gorbachenko, E.V. Kartamysheva, T.N. Luchkina, S.P. Podlesny, I.A. Loshkomoinikov, A.K. Minzhasova, Oilseed crops. Scientific and Technical Bulletin of the All-Russian Research Institute of Oilseed crops, 4(168), 67-76 (2016)

13. A.P. Kolotov, Oil flax in the Middle Urals (monograph). Cheboksary, 210 (2020)

14. G.G. Karpov, I.N. Porsev, S.G. Dunicheva, M.V. Karpova, I.A. Subbotin, New promising oil flax varieties in the phytosanitary technology of the Trans-Urals, Breeding and genetics: innovations and prospects: collection of articles based on the materials of the International Scientific and Practical Conference, dedicated to 100th anniversary of the Department of Breeding and Genetics, Gorki: BSAA, 61-64 (2020)

15. State register of breeding achievements approved for use (2020) URL: http://reestr.gossort.com/red/main/

16. T.A. Rozhmina, A.P. Kolotov, Oilseed crops. Scientific and Technical Bulletin of the All-Russian Research Institute of Oilseed crops, 1(173), 121-122 (2018)

17. N.V. Stepnykh, Increasing the income of agricultural enterprises by increasing the sowings of oilseed crops, Materials of the II All-Russian (national scientific and practical conference with international participation). Under the general editorship of Sukhanova S.F., 628-632 (2018)

18. T.A. Rozhmina, A.A. Zhuchenko, I.A. Kuzemkin et al., Achievements of science and technology of the agroindustrial Complex, 33(9), 28-31 (2019) DOI: 10.24411/02352451-2019-10906

19. S. Andruszczak, U. Gawik-Dziki, P. Craska et al., Plant Soil Environ, 61(6), 247-252 (2015)

20. M.E. Kurtenbach, E.N. Johnson, R.N. Gulden et al., Agronomy Journal, 111(4), 19041912 (2019)

21. M. Ludvicova, M. Griga, Czech J. Genet. Plant Breed., 51(4), 1230141 (2015) Doi: 10.17221/104/215-CJGPB

22. Methodology of conducting field agrotechnical experiments with oilseed crops/under the general editorship of V.M. Lukomets, cor. mem of the RAAS, Doctor of Agricultural Sciences, 327 (Krasnodar, 2010) 
23. B.A. Dospekhov, Methodology of field experience (with the basics of statistical processing of research results) 352 (Moscow, Alliance Publishing House, 2011) 